\title{
Deslocamento Na Fronteira: Possibilidades E Limites De Construções Identitárias ${ }^{1}$
}

\author{
Instrucciones para Autores Desplazamiento En La Frontera: Posibilidades \\ $Y$ Límites De Construcciones Identitarias \\ Instructions for Author Displacement at the Border: Possibilities and \\ Limitations of Identity Constructionss
}

\author{
Maria Cristina Lobregat ${ }^{2}$
}

\begin{abstract}
Resumo
Este artigo tenciona refletir sobre a construção da identidade dos brasileiros, conhecidos como "brasiguaios", que se deslocaram para o Paraguai há mais de três décadas e que, na atualidade, seguem o movimento de retorno. No mesmo caminho, será feita a discussão sobre as memórias individuais e as coletivas que marcam o conflito por terra, intensificado em 2008 e iniciado ainda nos anos de 1980, diante de duas mudanças políticas que envolveram os dois países (ditadura militar e governo democrático), colocando em reflexão o lugar político do Estado Nação. Para contextualizar os acontecimentos serão chamados dois nomes de pesquisadores como Lindomar Albuquerque e Celso Amorim Salim, que se dedicaram às temáticas de migração e imigração na fronteira Brasil/Paraguai e alinhavaram o contexto histórico dos fatos. A abordagem tem como objetivo pensar a construção da memória como representação a partir dos registros de textos (notícias em jornais locais e nacionais) que procuram interpretar, de um modo singular, os acontecimentos e marcar a construção de identidade dos brasileiros de forma significativa nos contextos de memória coletiva. No almejo da conclusão, é possível sinalizar uma disputa étnica em torno de um conflito por terra, sendo a dialética entre memoria individual e coletiva um dos pontos mais importantes para a fabricação de sentidos dos textos jornalísticos e no imaginário fronteiriço.
\end{abstract}

Palavras-Chave: brasiguaios; deslocamento; Estado Nação; fronteira; memória coletiva.

\section{Resumen}

Este artículo pretende reflexionar sobre la construcción de la identidad de los brasileños, conocidos como "brasiguaios", que se desplazaron para Paraguay desde hace más de tres décadas y que, en la actualidad, siguen el movimiento de retorno. En el mismo camino, se hará la discusión sobre las memorias individuales y las colectivas que marcan el conflicto por tierra, intensificado en 2008 e iniciado aún en los años 1980, ante dos cambios políticos que involucrar a los dos países (dictadura militar y gobierno democrático), poniendo en reflexión el lugar político del Estado Nación. Para contextualizar los acontecimientos serán llamados dos nombres de investigadores como Lindomar Albuquerque y Celso Amorim Salim, que se dedicaron a las temáticas de migración e inmigración en la frontera Brasil / Paraguay y alambraron el contexto histórico de los hechos. El enfoque tiene como objetivo pensar la construcción de la memoria como representación a partir de los registros de textos (noticias en periódicos locales y nacionales) que intentan interpretar, de un modo singular, los acontecimientos y marcar la construcción de identidad de los brasileños de forma significativa en los contextos

\footnotetext{
${ }^{1}$ Artigo apresentado no Simpósio Temático Políticas Públicas, diversidade cultural e descolonização, durante o II Seminário Latino-Americano de Estudos em Cultura - SEMLACult em Foz do Iguaçu/PR, Brasil, 2018.

${ }^{2}$ Mestre em Letras: linguagem e identidade; Universidade Federal do Acre - UFAC; Doutoranda pelo Programa de Pós -Graduação Sociedade, Cultura e Fronteiras; Universidade Estadual do Oeste do Paraná - UNIOESTE, Foz do Iguaçu, Paraná, Brasil , professora no Instituto Federal do Acre-IFAC, cristina.lobregat@gmail.com
} 
de memoria colectiva. En el anhelo de la conclusión, es posible señalar una disputa étnica en torno a un conflicto por tierra, siendo la dialéctica entre memoria individual y colectiva uno de los puntos más importantes para la fabricación de sentidos de los textos periodísticos y en el imaginario fronterizo.

Palabras claves: brasiguaios; desplazamiento; Estado Nación; frontera; memoria colectiva.

\begin{abstract}
This article intends to discuss the identity construction of Brazilian people, known as "brasiguaios", which moved to Paraguay over three decades ago and are returning nowadays to Brazil. In the same way, it discuss the individual and collective memories that mark the conflict for land, intensified in 2008 and initiated in 1980, in the face of two political changes that involved these two countries (military dictatorship and democratic government), bringing into debate the political position of the National State. To contextualize the events, it will be convened the researchers Lindomar Albuquerque and Celso Amorim Salim, which dedicated themselves to topics like Brazil/Paraguay border migration and immigration, and described the historical context of these events. This approach aims to meditate about memory construction as a representation from written records (journal local and national news) that try to interpret, in a singular way, the events and that define the identity construction of Brazilian people in a significant way in the collective memory contexts. On the way to conclusion, it is possible to bring over an ethnic dispute arround a land conflict, the dialectic between individual and collective memory being one of the most important points for the production of meanings of the journal records and in the frontier imaginary.
\end{abstract}

Keywords: Brasiguayan; offset; Nation State; border; collective memory.

\title{
1. Introdução
}

A língua tem indicado inequivocamente que a memória não é um instrumento para a exploração do passado; é antes, o meio. É o meio onde se deu a vivência, assim como o solo é o meio no qual as antigas cidades estão soterradas. Quem pretende se aproximar do próprio passado

(Walter Benjamin - Obras escolhidas: rua de mão única)

Escavar o passado é um ato necessário para entendermos as construções significativas de identidade e memória, sendo assim este artigo aborda essas questões e refere-se à pesquisa de doutoramento, que está em desenvolvimento, vinculada ao Programa de Pós-Graduação Sociedade, Cultura e Fronteiras, pela Universidade estadual do Oeste do Paraná -UNIOESTE. Embora, a pesquisa ainda esteja em seu formato embrionário, podemos alertar que ao observar as "dinâmicas" existentes na fronteira entre Brasil e Paraguai, foi possível encontrar diversas faces desta movimentação (brasileiros que trabalham no comércio, no Parque Industrial, latifundiários, arrendatários de terras, sem-terra e outros), sendo assim, nosso recorte envolve, especificamente, trabalhadores do campo, reconhecidos como agricultores, colonos e/ou "brasiguaios" nas colônias onde moravam antes de retornarem ao Brasil. Tornase necessário evidenciar que durante a pesquisa de Mestrado aconteceu o interesse pela 
temática que envolve o deslocamento, quando os sujeitos daquela pesquisa compunham o cenário de deslocamento de trabalhadores rurais do oeste paranaense em direção ao estado do Acre em busca de terra para trabalhar após a desapropriação de terras por Itaipu na década de 1980, muitos eram arrendatários e buscavam a posse de terra, entretanto, tínhamos notícias de que outros se deslocaram para o Paraguai.

Ao pensar na experiência de deslocamento daqueles que foram para o Paraguai houve o despertar de interesse por um segundo movimento: o de retorno. Após mais de três décadas de vivência nas colônias paraguaias, trabalhadores do campo retornam ao Brasil sem garantias ou direitos, com uma visibilidade unidimensional, generalizados e esquecidos. Diante de tais acontecimentos, o objetivo desta abordagem de pesquisa está em pensar a construção da memória, principalmente a coletiva, a partir dos registros de textos (notícias em jornais locais e nacionais e outras publicações) que procuram interpretar, de um modo singular, os fatos e marcar a construção de identidade dos brasileiros de forma significativa, atribuindo-lhes uma característica também singular que os denomina como "brasiguaios".

No intuito de saber mais, nos interessamos por diversos textos e produções acadêmicas, sendo que destacamos Lindomar Albuquerque e Celso Amorim Salim, dois pesquisadores que discutem a temática de deslocamento nesta fronteira. A partir da leitura de suas pesquisas, optamos em buscar em discursos jornalísticos os acontecimentos que envolveram a luta pela terra entre brasileiros e paraguaios, intensificada em 2005. A partir da escolha de textos destacamos os periódicos locais Nosso Tempo e Gazeta do Iguaçu ; como também os de tiragem nacional como Gazeta do Povo, Folha de São Paulo e Jornal do Brasil. Mas as produções abriram também a possibilidade de textos escritos por jornalistas, ainda na década de 80, como exemplo Brasiguaios: homens sem pátria, de Carlos Wagner, que consagrou a história de luta de trabalhadores rurais na fronteira entre Brasil/Paraguai e, mais ainda, também intensificou a identidade conhecida como "brasiguaio". Nesse sentido, este artigo traz uma abordagem teórico-metodológica pautada na reflexão e análise dos discursos de jornais locais e nacionais, textos acadêmicos e publicações independentes que envolveram os fatos e elaboraram a memória na fronteira. Com a interpretação destes discursos destacaremos a presença do poder político do Estado Nação, as disputas étnicas e as identidades daqueles que experimentaram a experiência no movimento de "ir" e "vir".

Diante da mesma proposta de análise, identificamos que a luta pela posse de terra é pauta nas construções de memória coletiva em situações de conflito. Essa memória pode ser individual ou coletiva, neste texto daremos ênfase à coletiva relacionando-a àquilo que os 
sujeitos sociais devem lembrar ou esquecer das suas experiências. Esse exercício interpretativo será possível a partir das leituras de Márcio Seligman-Silva e Joël Candau nos alertando que "[...] a memória coletiva tem também ela sido orquestrada, não menos do que a memória histórica [...]através de um processo permanente de eliminação e escolha" (CANDAU, 2005, p. 137). Com âncora na discussão de Candau perceberemos que no espaço de fronteira muitas interpretações dos fatos consolidam-se em memórias e ocupam um lugar de "verdade" no cenário.

Além de Candau, dialogamos também com Michel Foucault quando discute sobre a ordem do discurso, ou seja, as amarras invisíveis presentes em alguns textos fundamentais e fundantes para a construção de formas de pensar e ver os acontecimentos fronteiriços. Sabendo que ao falar sobre deslocamento na fronteira estamos vinculados às noções de poder exercido pelo Estado e seguimos buscando respostas em Norbert Elias para refletirmos sobre a movimentação na fronteira, bem como a luta pela posse de terra. Além disso, teremos um olhar atento aos textos que circularam na fronteira e marcaram aquilo que será lembrado e ao mesmo tempo esquecido no contexto, o que garante uma fabricação de sentido, identidade e memória aos sujeitos protagonistas dos eventos sociais, como também dão significado ao olhar daqueles que estão como espectadores dos acontecimentos.

\section{Deslocamento em seu contexto}

$\mathrm{Na}$ fronteira Brasil/Paraguai, localizada em Foz do Iguaçu, tornou-se lugar comum legitimar a relação entre brasileiros e paraguaios como pacífica e fraternal. Entretanto sabemos da existência, na história de ambos os países, conflitos marcados por lutas territoriais e ressentimentos que não foram esquecidos na memória nacional dos paraguaios. Também sabemos que há no imaginário nacional brasileiro o sentimento de superioridade em relação aos vizinhos. Nosso olhar será voltado a uma página da história desta fronteira que revela uma condição de perdas, de ganhos no movimento de "ir" e "vir", que chamamos deslocamento fronteiriço, a partir de discursos que produziram significados que dividem as formas de ver e sentir a presença do outro.

Pensaremos no sujeito da pesquisa como aquele que viveu e fez a história da fronteira a partir de trânsitos e lutas por terra para produzir. A partir deste propósito trazemos o pesquisador Celso Amorim Salim (1995), que em sua discussão sobre a imigração na América Latina (especificamente nesta fronteira) evidencia algumas informações e dados importantes para a compreensão dos deslocamentos ocorridos. Com base em estudos de Salim, podemos 
compreender que o movimento migratório na forneira tem raiz profunda e antiga " $[$...] desde o término da guerra da Tríplice Aliança (1864-1870), até os anos 50 deste século, com a concentração de terras em mãos do capital estrangeiro suportando a formação de latifúndios que exploravam a pecuária e recursos florestais [..]” (SALIM, 1995, p. 146). Portanto esse movimento tomou corpo na ditadura de Stroessner através de políticas prevendo a modernização agrícola dependendo da colonização com a distribuição de terras, isso forçaria o povoamento de "terras vazias" e integraria o Paraguai ao capitalismo em expansão. Ainda em Celso Amorim Salim foi possível ver que entre 1960 e 1983 foram implantadas 645 colônias no território paraguaio e a colonização agrícola "[...]atingiu seu ápice na década de 70[...]" (SALIM, 1995, p.149). Com a construção da Usina Hidroelétrica Itaipu houve também um fluxo de deslocamento de trabalhadores em busca de terra para plantar, pois grande parte do território da região oeste do Paraná foi alagada. Diante de tais questões factuais podemos perceber a participação dos Estados nessa movimentação de famílias brasileiras em busca de prosperidade através da atividade rural. Os Estados brasileiro e paraguaio conduziam a partir de políticas de colonização os corpos que compõem a fronteira impulsionando as mobilidades entre os territórios.

Procurando construir o texto com fortes características cronológicas, trazemos para a esteira histórica a pesquisa de José Lindomar Albuquerque que estudou as dinâmicas da fronteira Brasil/Paraguai dando ênfase ao movimento de retorno. $\mathrm{O}$ autor nos assegura que nas "[...]décadas de 1980 e 1990, milhares desses imigrantes voltaram para o Brasil[...]" (ALBUQUERQUE, 2010, p.68), e ainda salienta que este movimento de retorno foi bastante forte na fronteira com Mato Grosso do Sul, especificamente, no limite com Mundo Novo. Foi nesta situação que surgiu a palavra "brasiguaio" (WAGNER, 1989 e ALVES, 1990) em um evento com os trabalhadores que retornavam ao Brasil devido ao Plano Nacional de Reforma Agrária em 1985 (SALIM, 1995, p.153). O termo "brasiguaio" popularizou-se e tomou um espaço generalizado servindo para caracterizar os brasileiros que moravam no Paraguai e/ou os que retornavam ao Brasil.

Outro apontamento importante que José Lindomar nos indica é a ausência de dados demográficos precisos. As estimativas apresentadas em estudos não coincidem entre elas, nem mesmo com o censo do Instituto Brasileiro de Geografia e Estatística (IBGE) ou com o Ministério das Relações Exteriores. Isso pode ter como causa a ilegalidade dos brasileiros e a falta de controle na fronteira por parte dos governos brasileiro e paraguaio. Não há um instrumento eficiente capaz de quantificar o deslocamento fronteiriço, portanto, optamos por 
não usar dados quantificáveis para ilustrar esta mobilidade. O nosso interesse está inclinado aos motivos que levaram os brasileiros a escolherem o retorno ao Brasil e, consequentemente, nesses momentos de luta surge o movimento dos camponeses paraguaios no cenário dos jornais.

Lindomar Albuquerque salienta que com o término da ditadura de Stroessner houve a visibilidade das entidades representativas do movimento camponês que passaram a reivindicar uma mudança na estrutura fundiária no Paraguai, isso afetou a situação de alguns brasileiros que viviam nas colônias, pois muitos deles não possuíam as escrituras públicas. Em 2008, com a promessa de reforma agrária do governo de Fernando Lugo, os conflitos foram recorrentes, concentrando a atenção à luta dos campesinos paraguaios como principal motivo de retorno. Refletindo acerca dos aspectos identitários dos sujeitos que se deslocam, como também pelo uso de quase um adjetivo pátrio "brasiguaio" para denominá-los, consideramos a participação do poder do(s) Estado(s) na decisão de ir e de retornar. O movimento de retorno iniciado em 1985 acompanhou o embalar do novo governo, a esperança na democratização do país e a fé na reforma agrária. Especificamente nesta década algumas ações do Paraguai também empurraram os brasileiros para o retorno como por exemplo a lei de limites fronteiriços e soberania nacional que tramitava no Paraguai. O Estado, a partir de seus instrumentos e ferramentas políticas, possui um poder político que conduz a mobilidade dos corpos no sentido do "ir" e "vir". Ao legitimar esse poder, os retornados ficam suspensos diante de um poder simbólico sobre os corpos que compõem a fronteira Brasil/Paraguai.

Diante disso, abrimos a reflexão sobre a fabricação de comportamentos que traduzem a obediência, bem como um tipo de dominação que tornam os corpos úteis a serviço de uma política de colonização, a princípio, e a (des)colonização no século XXI no território paraguaio. Foram os Estados Nacionais de fronteira que geriram e gerem a vida daqueles que a habitam, desde 1950 com a "Marcha para o leste" e agora estão produzindo situações que criam o movimento contrário: o de retorno. Sendo assim, é perceptível a existência de uma dominação sobre os corpos para a ocupação dos territórios no sentido de mobilidade ou nãomobilidade.

Os grupos de trabalhadores rurais vivenciam um Estado e sentem a sua influência em processos experimentados no cotidiano da fronteira ou nos eventos históricos de mobilidades, mesmo que esta possa apresentar-se de maneira sutil e influenciar formas de ver e sentir essa presença. Buscamos em Norbert Elias a formação dos Estados Nacionais na obra Os Alemães (1997), na qual é visível a formação do Estado Alemão e do Estado Francês traçando as 
relações de poder que formaram o nacionalismo e, consequentemente, no caso francês, o vínculo desta formação com a ideia de civilização. Mas ao trazermos Elias para o debate, pensamos em um processo civilizatório para além dos limites da Europa chegando à América Latina, e diante dos processos civilizatórios vividos na fronteira Brasil/Paraguai, temos a concretude do pensamento teorizado por Elias.

Sabemos que a linha geral do pensamento de Elias concedeu uma reflexão sobre a criação do sentimento nacionalista com o surgimento do Estado Nação possuindo fortes tendências vinculadas à ideia de civilização, a partir disso percebemos a crença francesa do homem civilizado influenciando a América Latina por ser um espaço de colonização e conquistas dos países europeus. Norbert Elias na mesma obra, já mencionada, mostra-nos que houve uma mudança de atitude na sociedade francesa incluindo comportamentos que a aproximasse das características de um homem civilizado. Ao mesmo tempo que a civilidade era uma expressão do nacionalismo era também um modelo para outras sociedades, ou seja "[...] expressava, ao mesmo tempo, a crença em que a tradição nacional francesa consubstanciava e representava valores morais e outros, bem como realizações válidas para a humanidade como um todo”. (ELIAS, 1997, p.130)

Essas crenças francesas foram agregadas aos países colonizados na América do Sul, com isso os reconhecimentos entre si passam pelo valor do sentimento de ser ou não civilizado. Os caminhos percorridos pelos europeus foram reproduzidos pelos territórios latino-americanos e os Estados Modernos tornaram-se uma realidade diante de modelos europeus em territórios tropicais. No caso das relações do Brasil com o país vizinho, o Paraguai, é possível sentir o cheiro da superioridade imaginária do brasileiro em relação ao "outro", o que pode ser também o resquício da guerra da Tríplice Aliança simbolizando uma superioridade da nação brasileira e seus apoiadores. Esta superioridade imaginária está bastante latente nos textos que circularam a fronteira e o território nacional brasileiro, salientando a competência e a superioridade do brasileiro como produtor de grãos e salvador da economia paraguaia.

Dando um salto na cronologia histórica, ressaltamos que a partir dos anos dois mil, mas bem mais visível em 2008 com o governo de Fernando Lugo, houve uma intensificação nos noticiários trazendo os "brasiguaios" como protagonistas na história desta fronteira. Incansavelmente as notícias envolviam os conflitos entre os campesinos paraguaios e os agricultores brasileiros que moravam em colônias paraguaias. Os discursos que circularam a fronteira ressaltaram o movimento de retorno por ser provocado pela invasão dos campesinos 
em propriedades dos brasileiros, colocando a dúvida na legitimidade do processo de reforma agrária paraguaia.

Torna-se imperativo, nesse contexto, observar os discursos de jornais que trazem com convicção uma identidade que se arrastava desde 1985, a "brasiguaia". As notícias que tematizam a luta entre os brasileiros e paraguaios pela posse de terra, consolidam a identidade brasiguaia de forma generalizada não indicando nenhuma diferença entre as classes que se constituíram ao longo de tantos anos de colonização. Colocam as várias realidades como a do sem-terra, do arrendatário, do pequeno produtor e do latifundiário em um mesmo contexto, embora saibamos que as realidades sociais vividas por estes grupos distintos podem ter impulsionado o movimento de retorno. Sendo assim, essa identidade brasiguaia é singularizada o que simplifica não só ela, mas todo o contexto histórico na memória existente na fronteira.

\subsection{Os textos que marcam a memória e o esquecimento}

Em uma aula inaugural no Collège de France, em dezembro de 1970, Michel Foucault marcou seu lugar de fala e sua inquietação sobre a ordem do discurso supondo que "[...] em toda sociedade a produção do discurso é ao mesmo tempo controlada, selecionada, organizada e redistribuída[...]" (FOUCAULT, 2010, p.09), sendo que isso representa a expressão de poder que o discurso dispersa diante de sua materialidade. Seguindo as pistas de Foucault, pensaremos em nossa análise a partir os textos que circularam a fronteira Brasil/Paraguai e o território nacional marcando posicionamentos políticos e ideológicos, fixando identidades que podem ser metamorfoseadas, como por exemplo a identidade "brasiguaia".

Os enunciados aos quais nos referimos tratam não só do deslocamento migratório de brasileiros para o Paraguai e posterior retorno, mas também trazem em seus textos questões étnicas importantes para a nossa análise. Seguindo a discussão de Foucault (2010) há várias formas de controlar os discursos através da "exclusão e interdição" (FOUCAULT, 2010, p. 9) que formam uma grade complexa de proibições, que Foucault exemplifica com a sexualidade, razão e loucura. Contextualizando para o nosso objeto de análise, compreendemos o controle dos discursos que envolvem um suporte institucional, que é reforçado e conduzido por práticas sociais que estão vinculadas a instituições consolidadas. Assim, as bibliotecas, os livros, a escola, as publicações formam uma rede de significados que podem dar um tom de "verdade" aos discursos que seguem uma ordem. 
Para materializar, trazemos o jornal Nosso tempo, periódico iguaçuense, de tiragem semanal, datado em dezembro de 1980. Este destacava a colonização como fator que criava uma fronteira separando os brasileiros dos paraguaios e salientava o caráter de "negócio de terra" como instrumento de dominação do trabalhador do campo.

A colonização do Leste paraguaio por brasileiros tem fortes indícios de que tem sido atraída deliberadamente pelo governo daquele país, difundindo-se até mesmo uma avaliação de capacidade, segundo a qual os brasileiros têm mais experiência, mais disposição para o trabalho e, principalmente, mais recurso, o que não deixa de ser verdade. Por esse motivo, as empresas que venderam e vendem terras às vezes simplesmente negam-se a negociar com paraguaios, preferindo exclusivamente vender a brasileiros, podendo cobrar um preço muito mais elevado. Mas a situação legal dos brasileiros é quase sempre precária, e isso dá ampla margem de manobra, como a que conduz o migrante a pagar duas ou mais vezes pela terra. (NOSSO TEMPO, 1980, p.7 - grifo nosso)

O texto deste periódico sinaliza as intenções de negociar as terras no Leste paraguaio, bem como as manobras feitas pelas colonizadoras para promover a monocultura de exportação que aqueceria a economia paraguaia. Para isso, o migrante brasileiro apresentava o perfil necessário para o tipo de produção desejada pelo Estado paraguaio. É também visível que a crítica feita pelo jornal é um tipo de alerta de que as ilegalidades já existiam, que a posse de terra não se apresentava segura, assim as colonizadoras privadas eram as protagonistas de todo o processo de acolhimento dos trabalhadores brasileiros, mas que décadas mais tarde não garantiriam a posse do lote e resultaria em expulsão envolvendo uma luta entre agricultores brasileiros e campesinos paraguaios.

Fica evidente no enunciado deste periódico duas outras questões que separam os dois grupos étnicos: a força de trabalho do brasileiro como sendo superior devido a experiência com a monocultura, bem como seu poder de capital para negociar terras. Além de marcar a superioridade étnica do brasileiro, há também uma desconstrução da ideia de harmonia entre brasileiros e paraguaios, denunciando que é falsa a ideia de que se vive em "paz" na fronteira, pois há ainda muita disputa não só pelo espaço geográfico, mas também pelo espaço como sujeito histórico e, consequentemente, cultural. Nesse sentido podemos caracterizar essa relação como resquícios de uma memória coletiva diante do conflito conhecido como Guerra da Tríplice Aliança. Diante dos efeitos da guerra, é possível pensar com Joël Candau quando nos alerta sobre as hipóteses de lembranças que são construídas em um grupo social e ainda salienta que esse exercício pode ser considerado “[...] uma representação, uma forma de metamemória , quer dizer, um enunciado que membros de um grupo vão produzir a respeito de uma memória supostamente comum a todos os membros deste grupo [...]" (CANDAU, 2012, p.24), o que pode explicar a fronteira simbólica e de resistência do campesino 
paraguaio ao modelo de agricultura do brasileiro, deixando evidente que não é apenas uma luta por terra, mas também por questões culturais envolvendo a forma de relação do homem com a natureza. Na memória nacional paraguaia, a presença do brasileiro continua sendo uma ameaça ao povo paraguaio devido às suas estratégias de colonização.

Embora o jornal Nosso tempo seja considerado um jornal vanguardista e de denúncia, a presença da ideia de superioridade étnica brasileira é latente, mesmo que de forma branda. Além disso, a abordagem da reportagem nos remete à vitimização dos brasileiros em relação ao tratamento recebido e a ausência de direitos no território vizinho, o que resulta em uma identidade local como representação dos trabalhadores que não conseguiram se estabelecer com prosperidade no Paraguai, assumindo a identidade de "brasiguaios", vale ressaltar que essa construção discursiva acontece tanto em alguns textos jornalísticos quanto em muitos textos resultantes de pesquisas acadêmicas. Para Candau na situação de migração as memórias estão sempre presentes e "se deparando" com o outro, o que podemos chamar como um processo de alteridade, sendo que neste movimento de olhar para o outro é que se produz a identidade social (CANDAU, p.17). A identidade do brasileiro que vive no território paraguaio, especificamente no meio rural, o conhecido "brasiguaio", é vista como superior no ato de produzir e estocar para a importação, uma caraterística considerada superior dependendo do "local de fala" e da forma de ver a produção, o que seria para Foucault a ordem do discurso. O uso de venenos e o plantio de transgênicos não é uma forma aceita pelos campesinos paraguaios que alegam como um ato de destruição, tornando esse fato um argumento forte para a reforma agrária paraguaia baseada em conceitos de campesinato que respeita o espaço natural.

As reflexões de Candau sobre memória e identidade nos conduziu à percepção de que há a fabricação de sentidos no discurso do jornal Nosso Tempo quando produz narrativas referentes ao processo de migração de brasileiros. Os textos procuram, validar e confirmar uma suposta superioridade étnica, reforçando uma identidade do brasileiro como superior e do paraguaio como inferior, sendo que, tais ideias somam-se a outros discursos marcando uma "representação do real", termo usado por Candau para explicar as escolhas feitas pelos grupos sociais ao elegerem aquilo adequado a ser lembrado ou esquecido, um determinado tipo de "enquadramento da memória" bastante discutido por Pollak.

Ainda em busca de textos jornalísticos capazes de ordenarem sentidos diante das identidades na fronteira Brasil/Paraguai, como também em um contexto de construção de 
identidade, reproduzimos outra notícia do Jornal do Brasil, publicado em 10 de agosto de 2008, que reafirma a identidade dos brasileiros no Paraguai.

\begin{abstract}
"O brasileiro veio para colonizar o Paraguai e abrir novas fronteiras e hoje eu acredito que não tenha esta oportunidade mais. A oportunidade hoje é para quem está aqui, progredindo na agricultura" (Adelar Birk, agricultor). Opinião semelhante tem o engenheiro agrônomo brasileiro Edson da Silva. Formado no Brasil e morador de Foz do Iguaçu, na fronteira com Cidade do Leste, ele diz que hoje os brasileiros não vão mais colonizar o Paraguai, mas explorar o mercado de trabalho. [...] já que falta mão-de-obra paraguaia especializada para trabalhar no país, principalmente nas grandes propriedade produtoras de soja, milho e trigo[...] "o Paraguai é uma mercado muito vantajosos, porque o pessoal do Brasil que se forma tem uma disposição , tem uma vontade de trabalhar muito maior" (JORNAL DO BRASIL, 2008, p.12)
\end{abstract}

Logo no início da reportagem, o enunciado afirma através da voz de agricultores que o brasileiro possui como característica saliente, a de colonizador. Para afirmar com mais precisão, dando um tom de credibilidade, a reportagem traz a voz de um profissional, engenheiro agrônomo, que se refere a outro tipo de movimento na fronteira, pois é impulsionado pelas oportunidades existentes de trabalho. As formas de pensar o povo paraguaio, as formas de observar a cultura do outro, a forma de organização social e a política para quem vive no Paraguai, mostra na fala dos brasileiros o sentimento de superioridade em relação ao "outro", algo semelhante ao proposto no jornal anterior, datado de 1980. Sendo assim, os discursos construídos através dos meios de comunicação possuem o propósito de marcar a memória e fundar a identidade do paraguaio, que muitas vezes pode ser entendida como inferior.

No sentido de marcar as memórias a partir dos textos que são publicados no território brasileiro, podemos pensar em Candau quando discute as retóricas holistas, pois "Quando uma retórica holista remete a representações factuais supostamente compartilhadas por um grupo de indivíduos, há uma forte probabilidade de que seu grau de pertinência seja elevado" (CANDAU, 2012, p.39), com isso verificamos que a forma como funciona a memória coletiva está ligada à existência de memórias fortes e enraizadas dentro de um grupo social. A ideia de superioridade étnica do brasileiro em relação ao paraguaio revela um ressentimento do evento histórico, como a Guerra da Tríplice Aliança, que deixou a sensação de superioridade para os brasileiros, entretanto, a memória do povo paraguaio pode ser considerada como "memoria forte enraizada" (CANDAU, 2012, p.46) que guarda o ressentimento em relação ao brasileiro e torna-se uma explosão de sentidos quando em um momento atual será necessário lutar pelo seu sentimento de território nacional. 
Com isso percebemos que a funcionalidade da memória coletiva está ligada a certos fatores considerados "memórias fortes" dentro de um grupo ou sociedade. É evidente também que a memória individual tem um papel importante na construção de memórias coletivas, mas para que elas façam sentido no contexto de grupo, elas devem estar coerentes com um determinado fato a ser lembrado. Portanto, percorrendo jornais de circulação no Brasil, observamos a recorrente ideia de que o brasileiro fez o Paraguai crescer economicamente, o que demonstra que isso é a força do trabalho, aspecto não privilegiado na cultura indígena e de certa forma uma maneira de marcar a identidade do outro como inferior.

As construções discursivas presentes nos jornais brasileiros alinhavam na memória nacional a superioridade do brasileiro trazendo dados, números que consolidam a majestosa produção agrícola.

Em Alto Paraná está a maior concentração de "brasiguaios" [...] grupo que responde por quase $60 \%$ da produção paraguaia de soja, estimada em 7 milhões de toneladas na última safra. A maioria dos brasiguaios é de pequenos e médios produtores, com áreas de 50 a 200 hectares (o parque Ibirapuera, em São Paulo, tem 160 hectares). São filhos e remanescentes da colonização brasileira no leste paraguaio nos anos 1970, após o acordo para a construção de Itaipu. (Folha de São Paulo, 08/06/2008)

A expressividade e valor das toneladas de soja produzidas por brasileiros justificam a permanência deles no território. Fica no imaginário nacional brasileiro a sensação de vitimização, crueldade e injustiça do Estado paraguaio. Os fatos ficam resumidos, generalizados e carregados de significados ideológicos moldando a memória do conflito entre paraguaios (campesinos) e brasiguaios (produtores de soja). As vozes que se destacam nas reportagens são sempre as brasileiras: "Não sou contra a reforma agrária, só não quero invasão da minha propriedade, afirma Silva” (Folha de São Paulo, 08/06/2008); “Queremos apenas que respeitem os nossos direitos e que possamos trabalhar em paz. Nosso lugar não é aqui protestando, é na terra produzindo." (GAZETA DO POVO, 12/07/2011); “A ideia é mobilizar o país todo até que o governo atenda as nossas reivindicações. Queremos garantias para produzir, como proteção à propriedade privada e respeito às leis” (GAZETA DO POVO, 13/07/2011), sendo que o que se destaca nas falas dos brasileiros é a seriedade e o valor do trabalho, a produção está sempre em evidência e com isso o argumento de que a economia do Paraguai se sustenta através do trabalho do brasileiro, que neste momento não possui garantia de direitos, assumindo o papel de vítima e de injustiçado.

Além das reportagens que noticiavam os acontecimentos envolvendo o deslocamento inverso, trazemos a obra publicada em 1990, pelo jornalista Carlos Wagner, que situa a história envolvendo as fronteiras no Paraná e no Mato Grosso do Sul. O título do livro 
Brasiguaios: homens sem pátria sugere que houve nesse deslocamento fronteiriço o abandono do Estado brasileiro em relação à causa dos trabalhadores rurais. De caráter altamente político, Wagner traz em sua narrativa a concretização da palavra "brasiguaio" tornando-a vocábulo para caracterizar aqueles que retornavam do país vizinho. $\mathrm{O}$ autor descreve a saga da parcela de brasileiros que não estavam entre os latifundiários, eram os trabalhadores que não tinham terra no Brasil e não conseguiram no Paraguai. Na concepção de Wagner, os "brasiguaios" são aqueles que não possuem nem direitos brasileiros, nem paraguaios, são homens sem assistência e sem pátria, ideia que solidifica um conceito de "brasiguaio" que já não se aplica na atualidade. Nesse sentido, o discurso construído na obra forma a ideia de injustiça e manipulação política a serviço de interesses capitalistas na produção rural.

As construções de memórias a partir da experiência individual ficam marcadas nas narrativas individuais, ao mesmo tempo em que representam um grupo, uma memória coletiva, sendo assim “[...] não pode haver construção de uma memória coletiva se as memórias individuais não se abrem umas às outras visando objetivos comuns, tendo um mesmo horizonte de ação" (CANDAU, 2012, p.48), sendo assim, podemos dizer que as vozes individuais dos brasileiros servem para construir um todo representativo do conflito. Nesse aspecto, as notícias presentes nos jornais de circulação nacional consolidam o objetivo de fixar tanto uma memória representativa do conflito por terra, como as identidades dos brasiguaios e dos campesinos paraguaios.

Seguindo o pensamento de Candau, sabemos que a memória coletiva só é construída quando as memórias individuais perseguem objetivos comuns, ou melhor, a rememoração de um fato tem relação com os quadros sociais constituídos em torno de um grupo social, devendo haver a comunicação com os membros deste grupo. Neste processo "[...] a lembrança individual, sem cessar, submetida às transformações e reformulações [...] (CANDAU, 2012, p.49) assume sua característica coletiva, processo que facilitam tanto o ato de lembrar quanto de esquecer, sendo um exercício de representação. Toda essa comunicação envolve de certa forma os discursos construídos ao longo dos fatos históricos que recebem o tom e uma ordem que um determinado grupo social escolhe e, consequentemente, marca e define as formas de lembrar e de esquecer, o que poderá definir uma formação identitária.

\section{Considerações finais}

Para concluir o texto, mas não a pesquisa, procuramos nos distanciar da ilusão monológica daquele que produz o discurso, pois as formulações discursivas, os contextos 
históricos e sociais são mais presentes e responsáveis pela construção de significados diante daquilo que será ou não guardado na memória existente nesta fronteira Brasil/Paraguai. Mesmo sabendo que as memórias são individuais, acreditamos que seja necessário intensificar a discussão sobre as escolhas, as rejeições e as formas de constituir aquilo que é rememorável.

As representações sociais divulgadas nos textos de jornais procuram dar sentido ao mundo cotidiano da fronteira entre Brasil e Paraguai, deixando visível que estas interpretações sobre as memórias e as identidades (tanto a identidade do brasileiro/agricultor/ trabalhador quanto do paraguaio campesino/indígena/ preguiçoso) estão na arena política e econômica que, simultaneamente, desenvolvem uma identidade a partir da metamemória discutida por Candeau. Além disso, cristalizar o retorno dos brasileiros devido à luta de campesinato paraguaio também pode ser uma armadilha política no contexto da América Latina.

$\mathrm{Na}$ tentativa de finalizar, deixamos algumas respostas e muitas perguntas. Apreender sobre as relações fronteiriças pode abrir novos significados da fundação de identidades presentes nas relações entre os sujeitos sociais que habitam estes espaços. Sendo assim, sabemos que Joël Candau possui uma preocupação com as diferentes formas de socializar a memória, pois em sua obra "Memória e Identidade" deixa a interrogativa sobre como ocorre o contágio de ideias, o que nos remeteu a existência dos discursos que registram, descrevem e relatam os deslocamentos nas publicações de jornais e textos independentes. Podemos dizer que os enunciados que usamos para a análise são capazes de cristalizarem e funcionarem como âncoras de memórias, o que servirá “[...]para delimitar uma área de circulação das lembranças" (CANDAU, 2012, p.35).

Com isso, sinalizamos que a temática envolvendo discursos que cristalizam a memória e identidade não se esgota neste texto e ainda pode sofrer mudanças, tendo como ponto de partida a recusa ao homogêneo, ao igual sem respeitar as partes individuais. Chegamos no momento de considerar que no passado há muito a ser escavado, como Walter Benjamin nos sugere, sendo necessário, a partir dos discursos construídos, abrir uma dialética entre memória e identidade, sempre atentos que na fronteira Brasil/Paraguai a formação da identidade está muito ligada ao que se pode ou não lembrar. 


\section{Referências bibliográficas}

ALBUQUERQUE, J.C. L. A dinâmica das fronteiras: os brasiguaios na fronteira entre o Brasil e o Paraguai. São Paulo: Annablume, 2010.

Brasileiros representam 90\% da população de Estado paraguaio. Jornal do Brasil. 16 de abril de 2008. Disponível em: <http://www.jb.com.br/pais/noticias/2008/04/16/brasileirosrepresentam-90-da-populacao-de-estad0-paraguaio/ > Acesso em 10/08/2017

Brasiguaios vão às estradas protestar contra invasões. GAZETA DO POVO, Curitiba, 13/07/2011. Disponível em: <http://www.gazetadopovo.com.br/vida-ecidadania/brasiguaios-em-alerta- no- paraguai>. Acesso em 21/08/2017

CANDAU, J. Memória e identidade. São Paulo: Contexto, 2012. 269 p. (Obra Completa) Antropologia da memória. Lisboa, Portugal: Instituto Piaget, 2013. p. 123-201 (Capítulo de Livro)

Drama no Paraguai: brasileiros estão comendo o pão que o diabo amassou. Jornal Nosso Tempo. Foz do Iguaçu, p. 6, 03 a 10 de dezembro de 1980.

ELIAS, N. Os alemães: a luta pelo poder e a evolução do habitus nos séculos XIX e XX. Rio de Janeiro: Jorge Zahar Editor, 1997. p. 117-143 (Capítulo de Livro)

FOUCAULT, M. A ordem do discurso: aula inaugural no Collège de France, pronunciada em 2 de dezembro de 1970. São Paulo: LOYOLA, 2010. 79 p. (Obra Completa)

MACHIO, J. Brasiquaios se armam para a reforma de Lugo. Folha de São Paulo. São Paulo, 08 de junho de 2008. Disponível em: <http://www1.uol.com.br/fsp/mundo>. Acesso em: $14 / 09 / 2017$

POLLAK, M. Memória e identidade social. Estudos históricos, Rio de Janeiro, vol.05, n.10, 1992.

SALIM, C. A. A questão dos brasiguaios e o Mercosul. In: Emigração e Imigração internacionais no Brasil contemporâneo. Neide Lopes Patarra (coord.), São Paulo: FNUAP, 1995. 
PARO, D. Quien son los “brasiguaios"? Gazeta do Povo, Curitiba, 14/05/2010. Disponível em: <http://www.gazetadopovo.com.br/cadernog/quien-son-los brasiguaios>. Acesso em $08 / 08 / 2017$

SAYAD, A. A imigração ou os paradoxos da alteridade. São Paulo: Edusp. 1998. p.11(Prefácio)

SELIGMANN-SILVA, M. Reflexões sobre a memória, a história e o esquecimento in. História, memória e literatura: o Testemunho na Era das Catástrofes. Campinas, SP: Editora da Unicamp, 2003. p. 59-90 (Capítulo de Livro)

SPRANDEL. M. A., Brasileiros na fronteira com o Paraguai. Estudos Avançados, $\mathrm{n}^{\circ} 20$, 2006.

WURMEISTER, F. Brasiguaios em alerta no Paraguai. GAZETA DO POVO, Curitiba, 12/07/2011. Disponível em: <http://www.gazetadopovo.com.br/vida-e-cidadania/brasiguaiosem-alerta- no- paraguai>. Acesso em 21/08/2017

WAGNER, C. Brasiguaios: homens sem pátria. Petrópolis, RJ: Vozes, 1989. 86 p. (Obra Completa) 